\title{
Sources of Carbonaceous Materials in the Airborne Particulate Matter of Dhaka
}

\author{
Bilkis A. Begum, Anwar Hossain ${ }^{1)}$, Golam Saroar ${ }^{2)}$, Swapan K. Biswas ${ }^{2)}$, Md. Nasiruddin ${ }^{2)}$, \\ Nurun Nahar ${ }^{1)}$, Zohir Chowdury ${ }^{3)}$ and Philip K. Hopke ${ }^{4), *}$ \\ Chemistry Division, Atomic Energy Centre, P.O. Box 164, Dhaka-1000 \\ ${ }^{1)}$ Chemistry Department, JahangirNagar University \\ ${ }^{2)}$ Clean Air and Sustainable Environment, Department of Environment, Agargaon, Dhaka \\ ${ }^{3)}$ Graduate School of Public Health, San Diego State University, San Diego, CA \\ ${ }^{4)}$ Center for air Resource Engineering and Science, Clarkson University, NY, USA \\ *Corresponding author. Tel: +1-315-268-3861, E-mail: hopkepk@clarkson.edu
}

\begin{abstract}
To explore the sources of carbonaceous material in the airborne particulate matter (PM), comprehensive PM sampling was performed (3 to 14 January 2010) at a traffic hot spot site (HS), Farm Gate, Dhaka using several samplers: AirMetrics MiniVol (for $\mathrm{PM}_{10}$ and $\mathrm{PM}_{2.5}$ ) and MOUDI (for size fractionated submicron PM). Long-term PM data (April 2000 to March 2006 and April 2000 to March 2010 in two size fractions $\left(\mathrm{PM}_{2.2}\right.$ and $\left.\mathrm{PM}_{2.2-10}\right)$ obtained from two air quality-monitoring stations, one at Farm Gate (HS) and another at a semi-residential (SR) area (Atomic Energy Centre, Dhaka Campus, (AECD)), respectively were also analyzed. The long-term PM trend shows that fine particulate matter concentrations have decreased over time as a result of government policy interventions even with increasing vehicles on the road. The ratio of $\mathrm{PM}_{2.5} / \mathrm{PM}_{10}$ showed that the average $\mathrm{PM}_{2.5}$ mass was about $78 \%$ of the $\mathrm{PM}_{10}$ mass. It was also found that about $63 \%$ of $\mathrm{PM}_{2.5}$ mass is $\mathrm{PM}_{1}$. The total contribution of $\mathrm{BC}$ to $\mathrm{PM}_{2.5}$ is about $16 \%$ and showed a decreasing trend over the years. It was observed that $\mathrm{PM}_{1}$ fractions contained the major amount of carbonaceous materials, which mainly originated from high temperature combustion process in the $\mathrm{PM}_{2.5}$. From the IMPROVE TOR protocol carbon fraction analysis, it was observed that emissions from gasoline vehicles contributed to $\mathrm{PM}_{1}$ given the high abundance of EC1 and OC2 and the contribution of diesel to $\mathrm{PM}_{1}$ is minimal as indicated by the low abundance of OC1 and EC2. Source apportionment results also show that vehicular exhaust is the largest contributors to PM in Dhaka. There is also transported $\mathrm{PM}_{2.2}$ from regional sources. With the increasing economic activities and recent GDP growth, the number of vehicles and brick kilns has significantly increased in and around Dhaka. Further action will
\end{abstract}

be required to further reduce PM-related air pollution in Dhaka.

Key words: Particulate matter, Dhaka, Source apportionment, PMF, Size distribution

\section{INTRODUCTION}

Black carbon (BC) and elemental carbon (EC) originate from the incomplete combustion of carbonaceous fuel. They are used to describe aspects of ambient particulate matter. However, these two terms are actually based on its measurement technique namely, thermooptical and optical techniques (Poschl, 2005). BC has received increasing attention in recent years because of its potential to contribute to global warming, carries carcinogenic compounds, and causes serious health risks (Ramanathan and Carmichael, 2008; Koelmans et al., 2006; Hansen and Nazarenko, 2004; Jacobson, 2001). Positive aerosol radiative forcing arises from absorption of solar radiation by black carbon. The significant impact of light absorbing particles such as BC and dust involves the vertical redistribution of the solar radiation between the surface and the lower atmosphere, quantitatively resembling the nuclear winter forcing (UNEP and C4, 2002). Black carbon (BC) can act in two ways. First as a direct absorber of visible light that provides direct warming in the lower atmosphere. Secondly, the deposition of black carbon on ice or snow such as on Himalayan glaciers (Kehrwald et al., 2008) is part of what is causing them to rapidly melt. BC may also influence climate indirectly on a regional scale by altering the monsoon circulation and hydrological cycle. Thus, there are good reasons to understand the extent and sources of $\mathrm{BC}$.

$\mathrm{BC}$ in indoor environments is largely due to cooking with biofuels such as wood, dung, and crop residue. In 
the ambient atmosphere, it is due to fossil fuel combustion (diesel and coal), open biomass burning (associated with deforestation and crop residue burning and cooking with biofuels (Andreae and Crutzen, 1997).

Among the suite of air pollutants, particulate matter (PM) is thought to be the most important pollutant in Dhaka with respect to health effects and reduced urban visibility. In a previous study, Biswas et al. (2001) found that approximately $40 \%$ of fine $\mathrm{PM}(<2.5 \mu \mathrm{m})$ is BC. The important sources of PM in Dhaka were identified as diesel-powered vehicles, two-stroke engine gasoline vehicles, and brick kilns (Begum et al., 2006a, 2005a, 2004; Salam et al., 2003). These studies have suggested that motorized transport vehicles were the single largest contributor to particulate air pollution especially to fine particulate matter concentrations in Dhaka. Policy interventions including the conversion of vehicles to compressed natural gas (CNG) has reduced the vehicular contributions (Begum et al., 2008). Among other policy actions, gasoline-powered twostroke, three-wheel vehicles were banned leading to reduced black smoke (Begum et al., 2008). Buses older than 20 years have also been banned and mechanic training programs have been implemented to improve vehicle maintenance.

Although the growth in the number of motorized vehicles in Dhaka has been about $10 \%$ year for last several years, the contribution from vehicles has not increased linearly with vehicular numbers (Begum et $a l .$, 2011a). The majority of private cars that ran on gasoline have been converted to CNG. Additionally, some diesel buses and trucks have also been converted to CNG largely because of the fuel price differential. However, because of electrical power problems, there are many diesel powered generators.

In addition, increasing economic activity has generated a high demand for construction materials including fired bricks. To meet this enhanced demand, there has been an increased number of brick kilns around Dhaka. The majority of brick making technology used fixed chimney kilns. These kilns use high sulfur coal and wood. Wood combustion is less energy efficient resulting in significant air pollution in Dhaka.

The carbonaceous fraction of PM in Dhaka has been less comprehensively studied than the inorganic components. To reduce carbonaceous PM, the emission sources must be known. Source identification and apportionment can be obtained through the analysis of the chemical characteristics of BC containing particulate matter.

Understanding characteristics of $\mathrm{BC}$ in submicron particles $\left(\mathrm{PM}_{1}: \mathrm{D}_{\mathrm{p}}<1 \mu \mathrm{m}\right)$ is important because the leading removal mechanism of ultrafine particles $(<100 \mathrm{~nm})$ is agglomeration to form fine particles.
Thus, measuring size distributions and analyzing BC fractions can be useful in determining the sources of those particles (Kim et al., 2011).

In previous studies (Begum et al., 2011a, 2005, 2004) on Dhaka fine particles, elemental compositions have been analyzed to identify potential sources of such particles. Only a few studies are conducted on carbonaceous particles. The present study combines measurement of $\mathrm{BC}$ fractions in fine PM and ultrafine PM along with the available information on size resolve PM sources. Although this study focuses mainly on the concentrations of $\mathrm{OC}$ and $\mathrm{EC}$ in $\mathrm{PM}_{2.5}$ and $\mathrm{PM}_{1}$ to better understand the $\mathrm{BC}$ emission sources, general trends of PM and $\mathrm{BC}$ concentrations as well as their possible sources are discussed. The objectives of this study are 1) to measure the concentration of $\mathrm{OC}$ and $\mathrm{BC}$ in fine and ultrafine particles at traffic intensive urban area in Dhaka, 2) to observe the relationship between the $\mathrm{OC}, \mathrm{EC}$ concentrations of fine and ultrafine particles 3) to identify the sources of OC and EC in UFPs and FPs and 4) trends and sources of PM pollution in an urban environment in Dhaka. The present results are discussed in the context of the previous source apportionment studies, especially of combustion sources, to relate the particulate air quality status with different policy interventions previously undertaken by the Government to reduce air pollution.

\section{MATERIALS AND METHODS}

\section{1 Sampling}

Fig. 1 shows the location of two sampling sites and the meteorological station in Dhaka, where long term PM samples have been collected over past decade. The hot spot site in Dhaka (HS) is a high traffic area located at Farm Gate adjacent to the intersection of several main roads typically carrying high volumes of traffic (Latitude: $23.76^{\circ} \mathrm{N}$; Longitude: $90.39^{\circ} \mathrm{E}$ ). The semiresidential area $(\mathrm{SR})$ (Latitude: $23.77^{\circ} \mathrm{N}$; Longitude $90.38^{\circ} \mathrm{E}$ ) in Dhaka is located in the Atomic Energy Centre, Dhaka (AECD) campus building with moderate traffic. Long term sampling (April 2000 to March 2006 at HS site and April 2000 to March 2010 at SR site) at both the sites were performed using a 'Gent' stacked filter sampler (Hopke et al., 1997) capable of collecting air particulate samples in coarse (2.2 to 10 $\mu \mathrm{m})$ and fine $(2.2 \mu \mathrm{m})$ size fractions. The sampling protocol was described by Begum et al. (2011a).

For the ultrafine particulate sampling campaign, two MOUDI and three AirMetrics MiniVol samplers were used. The samplers were placed on the flat roof of the guardhouse of the Bangladesh Agricultural Research Council (BARC) at Farm Gate. 


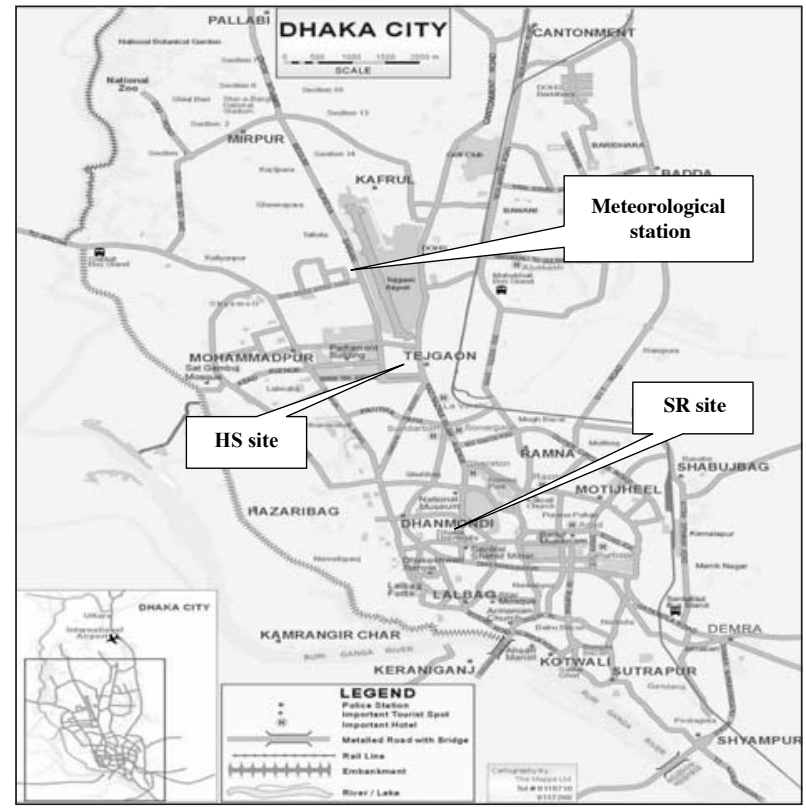

Fig. 1. Map of Dhaka, Bangladesh showing the locations of the two sampling sites (HS site and SR site).

The10-stage micro-orifice uniform deposit impactors (MOUDIs, MSP Corp., Model 100) were operated in parallel for consecutive 24 hour periods from 4 January to 13 January 2010 to collect a total of 10 samples. The cut points for the 10 stages are $18,10,5.6$, $3.2,1.8,1.0,0.56,0.32,0.18,0.1$ and $0.056-\mu \mathrm{m}$. However, an AIHL-design cyclone separator (John and Reischl, 1980) was connected upstream to each MOUDI to remove large particles having a 50\% aerodynamic cutoff diameter at $1.8 \mu \mathrm{m}$ before the air passed through the MOUDI impactors at a flowrate of $30 \mathrm{~L} / \mathrm{min}$. The cyclone was used to prevent particle bounce in the upper stages of the MOUDI since our interest in the study was to quantify mostly $\mathrm{PM}_{1.0}$ and smaller size ranges. The AIHL cyclone was used to suppress particle bounce from the upper stages of the impactors. Particles in the aerodynamic diameter size range of 0.056 to $1.8 \mu \mathrm{m}$ were collected in impaction stages 5 through 10 of the impactors. All 10 stages of the impactors were in place during the experiment but only the lower 6 stages collected meaningful samples because of the cyclone separator upstream of the impactors. The flow rate, and start and end time were recorded to allow the total volumes and mass concentrations to be calculated.

One impactor was loaded with aluminum foil substrates (MSP Corp., $47 \mathrm{~mm}$ diameter) and a $47 \mathrm{~mm}$ diameter quartz fiber backup filter. The second impactor was operated with PTFE impaction substrates and a backup filter (47 mm diameter, Teflo filters (Pall Corp.), $2.0 \mu \mathrm{m}$ pore size). The foil impaction substrates and quartz fiber filters were baked before use in order to lower their carbon blank values, since these materials were dedicated to the analysis of carbonaceous aerosol species; foil substrates were baked for 48 hours at $500^{\circ} \mathrm{C}$, and quartz fiber filters were baked for 12 hours at $500^{\circ} \mathrm{C}$. To avoid contamination by organic compounds, no grease or oil was applied to the impaction substrates. Following sample collection, filter samples and samples on impaction substrates were placed in petri dishes, and then frozen immediately until subsequent analysis.

Two AirMetrics MiniVol samplers were used to collect $\mathrm{PM}_{10}$ and $\mathrm{PM}_{2.5}$ on Teflon filters and a third MiniVol sampler was used to collect $\mathrm{PM}_{2.5}$ on quartz filters for subsequent compositional analysis parallel to the MOUDI sampling.

\section{2 PM Mass, BC and Carbon Fraction Analysis}

The masses of the samples were determined by weighing the Teflon filters before and after their exposure. A ${ }^{210} \mathrm{Po}$ (alpha emitter) electrostatic charge eliminator (STATICMASTER) was used to eliminate the static charge accumulated on the filters before each weighing. Elemental analyses were performed on the Teflon filters using PIXE (Cohen et al., 1996), and XRF methods in GNS Science, New Zealand and Clarkson University, NY, USA, respectively. These methods are described in detail by Landsberger and Creatchmam (1998).

Carbonaceous materials collected on the $\mathrm{PM}_{2.5}$ quartz filters were analyzed via IMPROVE/TOR protocol (Chow et al., 2008, 2004, 1993) for eight temperature resolved carbon fractions (Atmoslytic model DRI2100A). This protocol provides concentrations of carbon in four organic carbon fractions $(\mathrm{OC} 1, \mathrm{OC} 2$, OC3, OC3), three elemental carbon fractions (EC1, EC2, EC3) and pyrolyzed carbon (OP). The samples which were collected on Teflon filters in $\mathrm{PM}_{2.5}$ were analyzed by an EEL-type Smoke Stain Reflectometer (Diffusion Systems, Ltd) to measure BC. Secondary standards of known black carbon concentrations were used to calibrate the reflectometer (Biswas et al., 2003). The aluminum foil substrates (MOUDI sampler) were analyzed via IMPROVE/TOR protocol (Chow et al., 2008, 2004, 1993) for eight temperature resolved carbon fractions.

\section{RESULTS AND DISCUSSION}

\section{1 Meteorological Condition}

In Bangladesh, the climate is characterized by high temperatures and high humidity for most of the year, 
and distinctly marked seasonal variations in precipitation. Based on the meteorology, the year can be divided into four seasons, pre-monsoon (March-May), monsoon (June-September), post-monsoon (October-November) and winter (December-February) (Salam et al., 2003). The winter season is characterized by dry soil conditions, lower relative humidity, scanty rainfall and low northwesterly winds. The meteorological data used in this study was obtained from a local meteorological station that is located about 2 and 5 kilometers north of the hot spot (HS) and semi-residential(SR) sites, respectively.

Dhaka has a sub-tropical climate and in under the influence of the strong southwest or summer monsoon and weak northeast or winter monsoon. It has been understood from last few years of air quality monitoring, the air quality level of the city greatly influenced by the Asian monsoon. The air quality characteristics in Dhaka shows distinct seasonal variations, with high pollution episodes observed during the winter, while summer has relatively cleaner ambient air. During the dry winter and part of the post-monsoon season, the strength of north and northwesterly winds coming from India, Nepal and Southeastern China to the Bay of Bengal through Bangladesh can transport pollutants to the city. Moreover, during this season, wind speeds are low so that locally emitted pollutants are not well dispersed into the downwind area. Mixing heights of the boundary layer are important factors influencing the dispersion of pollutants.

\section{2 PM, BC, and EC Concentrations from 1-14 January 2010}

Samples were collected by three AirMetrics MiniVol samplers and the two MOUDI samplers. During the study period, the daily $\mathrm{PM}_{2.5}$ and $\mathrm{PM}_{10}$ values (Table 1) were higher than the $24 \mathrm{~h}$ average Bangladesh National Ambient Air Quality Standard (BNAAQS), which were set at $65 \mu \mathrm{g} / \mathrm{m}^{3}$ and $150 \mu \mathrm{g} / \mathrm{m}^{3}$, respectively. The

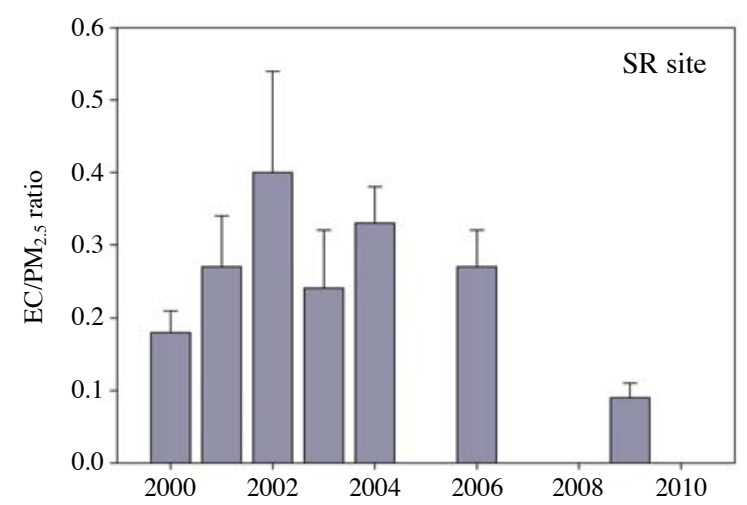

ratios of $\mathrm{EC} / \mathrm{PM}_{2.5}$ concentrations for the intensive study and for the same period in previous years were calculated and compared (Fig. 2). It was observed that the ratios have decreased after 2002. Although there is evidence that $\mathrm{BC}$ comes from the transboundary sources, especially during winter (Begum et al., 2011a, b, 2008; Ramanathan and Carmichael, 2008), it has significant local sources. BC concentrations were observed to vary from month to month depending on the meteorological conditions. It has been found that the concentration has decreased relative to previous years as a result of policies adopted by the government (Begum, 2006a).

$\mathrm{PM}$ and $\mathrm{BC}$ concentrations in the AirMetrics and MOUDI samples were compared. Fig. 3 shows mass ratios for different fractions of PM during the period of 4 January to 13 January 2010. From the average mass ratios of different $\mathrm{PM}$ fractions, it was observed that about $78 \%$ of $\mathrm{PM}_{10}$ is $\mathrm{PM}_{2.5}$ and about $63 \%$ of $\mathrm{PM}_{2.5}$ is $\mathrm{PM}_{1}$. It can be seen that the $\mathrm{BC}$ and EC masses are concentrated mainly in the $\mathrm{PM}_{1}$ fractions (Fig. $3)$. Thus, most of the BC mass was in the accumulation mode (0.1-1 $\mu \mathrm{m}$ diameter). Prior studies (Begum et al., 2006a, b; Salam, 2003) suggested that high EC

Table 1. Mass concentrations $\left(\mu \mathrm{g} / \mathrm{m}^{3}\right)$ in different fractions of PM during 4 to13 January 2010.

\begin{tabular}{cccc}
\hline \multirow{2}{*}{ Date } & \multicolumn{2}{c}{ Air metrics } & \\
\cline { 2 - 3 } & $\mathrm{PM}_{10}$ & $\mathrm{PM}_{2.5}$ & $\mathrm{PM}_{1}$ \\
\hline $01 / 04 / 2010$ & 339 & 267 & 177 \\
$01 / 05 / 2010$ & 294 & 252 & 161 \\
$01 / 06 / 2010$ & 359 & 330 & 166 \\
$01 / 07 / 2010$ & 303 & 234 & 150 \\
$01 / 08 / 2010$ & 328 & 227 & 132 \\
$01 / 09 / 2010$ & 255 & 183 & 126 \\
$01 / 10 / 2010$ & 267 & 207 & 141 \\
$01 / 11 / 2010$ & 271 & 211 & 147 \\
$01 / 12 / 2010$ & 269 & 208 & 126 \\
$01 / 13 / 2010$ & 327 & 248 & 159 \\
\hline
\end{tabular}

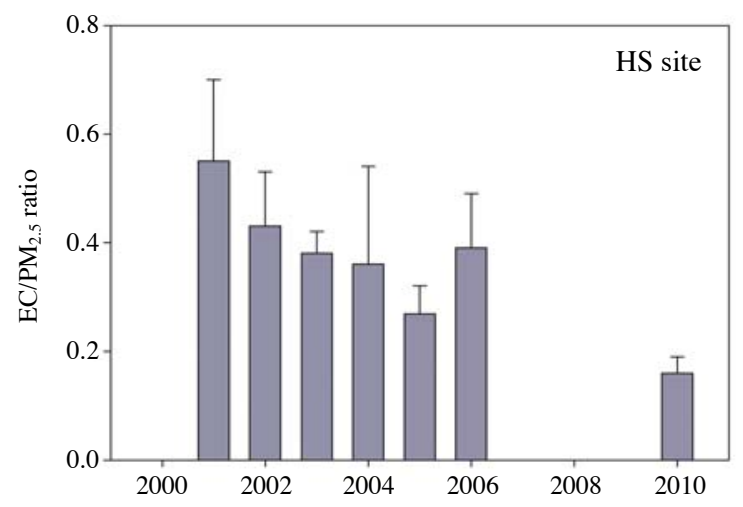

Fig. 2. Variation of $\mathrm{EC} / \mathrm{PM}_{2.5}$ ratio in different years from 1 to 14 January. 

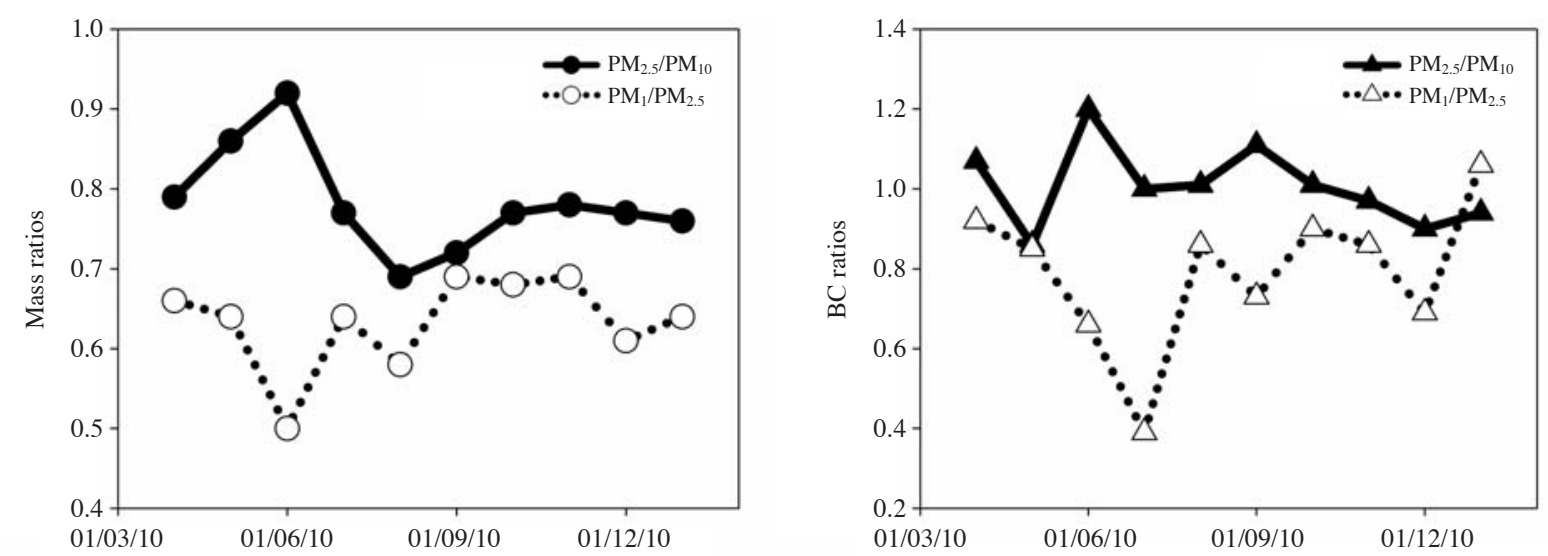

Fig. 3. Mass ratios for different fractions of PM during the January 2010.

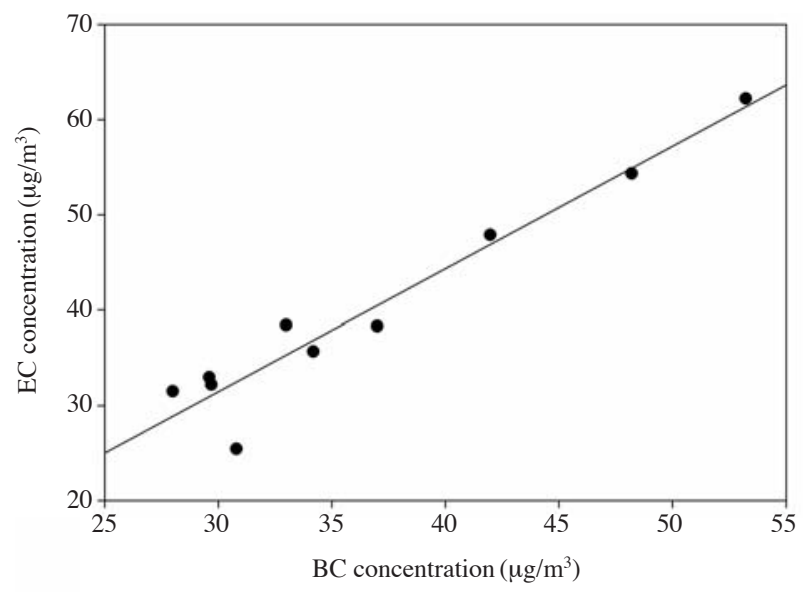

Fig. 4. Relation between EC and BC during January 2010.

contributions come mainly from the diesel trucks, petrol vehicle, two-stroke motorcycles, diesel-powered generators, open burning incinerators, and brick kilns.

\section{3 OC, EC, and TC Components for Identification of Sources}

Black carbon (BC) and elemental carbon (EC) in airborne particulate matter originate from the incomplete combustion of carbonaceous fuel. These terms are used to describe aspects of ambient particulate matter. However, they are not interchangeable because they are each defined by the way they are measured. Salako et al. (2011) report the variability of EC and BC in a number of locations across Asia and the South Pacific region. It was found that the $\mathrm{BC}$ concentrations were comparable with the EC values (slope $=1.1, \mathrm{r}^{2}=0.91$ ) (Fig. 4). The mass absorption coefficient that is used for $\mathrm{BC}$ calculation was $10.98 \mathrm{~m}^{2} / \mathrm{g}$ (Biswas et al., 2003). The two major classes of sources for EC and OC, fos- sil fuels and biomass based fuels exhibit distinctly different EC/TC and K/EC ratios allowing for source contributions to be estimated for EC and OC in the aerosol. Emissions from diesel engines as well as from oil- and coal-fired stationary sources exhibit EC/TC ratios in the range of 0.6-0.7 (Rau, 1989; Williams et al., 1989; Cass et al., 1982). It was found that K/EC ratio is 0.1 (Salam et al., 2003) for $\mathrm{PM}_{2.5}$, that indicate little influence from biofuel sources (Table 2). In smoke from biomass fires, the $\mathrm{K} / \mathrm{BC}$ ratio is characteristically higher than for the other sources of EC. This K/EC ratio (rural sites) varies from 0.22 to 1.4 depending on the kitchen environment and the fuel types (Samir, 2007; Venkaraman et al., 2002; Maenhaut et al., 1996). Hence, it can be concluded that biomass fuel combustion is not a major source of EC in Dhaka urban atmosphere.

EC has different sources such as diesel engine emissions, fossil fuel combustion at low burning efficiency and biomass burning. Figs. 5 and 6 show the fraction of total carbon contributed by each of the six carbon fractions for each sample $(\mathrm{EC} 3=0)$ collected with the AirMetrics and MOUDI samplers, respectively. The abundance of EC1 is generally higher in gasoline vehicles than in diesel vehicles (Watson et al., 1994). Similarly the $\mathrm{OC} 1$ abundance is higher in the diesel fueled relative to gasoline fueled and OC2 would be higher in gasoline emissions compared to diesel. In the present study, it was found that the contribution of gasoline is much higher than diesel. This finding could be due to banning of heavy duty diesel trucks in Dhaka city during daytime and use of gasoline during starting of CNG converted engines. The contribution of EC from compressed natural gas (CNG) would be much less.

The population of motorized vehicles in Dhaka is more than 560,000 up to 2010 and average annual 
Table 2. Ratios of $\mathrm{EC} / \mathrm{TC}$ and $\mathrm{K} / \mathrm{EC}$ in $\mathrm{PM}_{2.5}$ and $\mathrm{PM}_{1}$ fractions during the study period.

\begin{tabular}{|c|c|c|c|c|c|c|c|c|c|c|}
\hline \multirow{3}{*}{ Date } & \multicolumn{5}{|c|}{ Air metrics } & \multicolumn{5}{|c|}{ MOUDI } \\
\hline & $\mathrm{EC}$ & $\mathrm{K}$ & $\mathrm{OC}$ & \multirow{2}{*}{$\mathrm{EC} / \mathrm{TC}$} & \multirow{2}{*}{$\mathrm{K} / \mathrm{EC}$} & $\mathrm{EC}$ & $\mathrm{K}$ & $\mathrm{OC}$ & \multirow{2}{*}{$\mathrm{EC} / \mathrm{TC}$} & \multirow{2}{*}{$\mathrm{K} / \mathrm{EC}$} \\
\hline & \multicolumn{3}{|c|}{$\mu \mathrm{g} / \mathrm{m}^{3}$} & & & \multicolumn{3}{|c|}{$\mu \mathrm{g} / \mathrm{m}^{3}$} & & \\
\hline $01 / 04 / 2010$ & 38.3 & 3.43 & 35.2 & 0.52 & 0.09 & 34.0 & 2.60 & 27.6 & 0.55 & 0.08 \\
\hline $01 / 05 / 2010$ & 25.4 & 3.42 & 29.6 & 0.46 & 0.13 & 26.3 & 2.43 & 25.0 & 0.51 & 0.09 \\
\hline $01 / 06 / 2010$ & 62.2 & 4.79 & 51.1 & 0.55 & 0.08 & 34.9 & 3.17 & 25.2 & 0.58 & 0.09 \\
\hline $01 / 07 / 2010$ & 47.9 & 4.82 & 37.8 & 0.56 & 0.10 & 16.5 & 2.83 & 17.2 & 0.49 & 0.17 \\
\hline $01 / 08 / 2010$ & 54.3 & 4.32 & 36.4 & 0.60 & 0.08 & 41.2 & 2.37 & 25.2 & 0.62 & 0.06 \\
\hline $01 / 09 / 2010$ & 35.7 & 3.02 & 22.0 & 0.62 & 0.08 & 24.9 & 2.76 & 13.4 & 0.65 & 0.11 \\
\hline $01 / 10 / 2010$ & 32.2 & 3.66 & 25.4 & 0.56 & 0.11 & 26.7 & 2.42 & 14.0 & 0.66 & 0.09 \\
\hline $01 / 11 / 2010$ & 33.0 & 2.91 & 22.8 & 0.59 & 0.09 & 25.3 & 2.13 & 16.4 & 0.61 & 0.08 \\
\hline $01 / 12 / 2010$ & 31.5 & 2.64 & 22.8 & 0.58 & 0.08 & 19.4 & 1.92 & 13.6 & 0.59 & 0.10 \\
\hline $01 / 13 / 2010$ & 38.4 & 3.40 & 28.5 & 0.57 & 0.09 & 35.0 & 2.19 & 20.9 & 0.63 & 0.06 \\
\hline
\end{tabular}

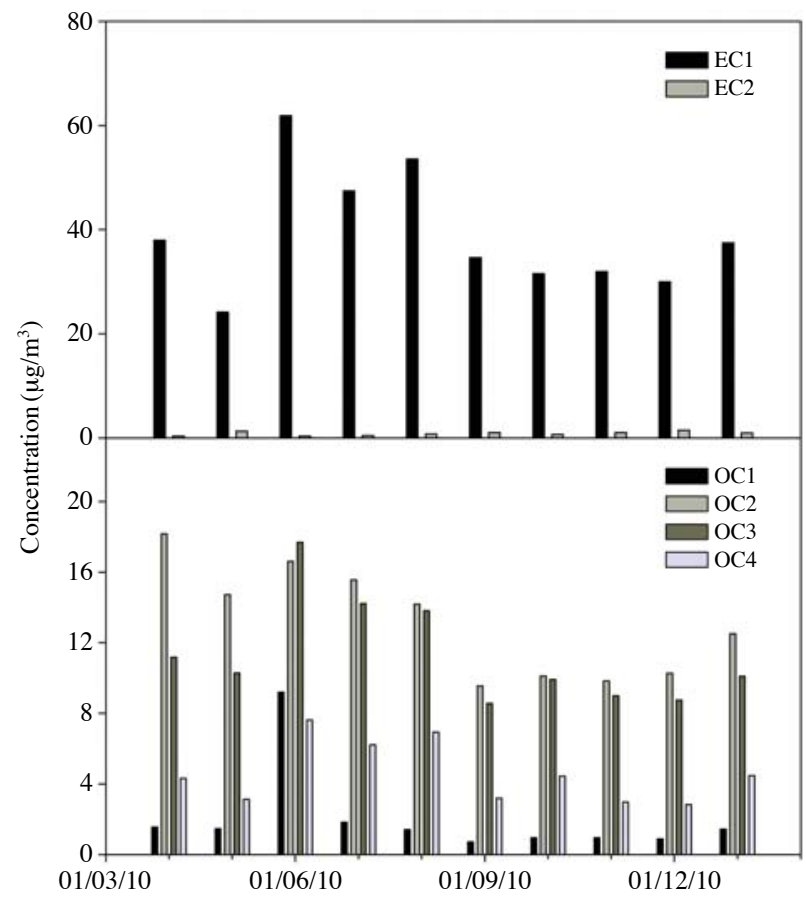

Fig. 5. Fractions of $\mathrm{OC} 1, \mathrm{OC} 2, \mathrm{OC} 3, \mathrm{OC} 4, \mathrm{EC} 1$, and $\mathrm{EC} 2$ in $\mathrm{PM}_{2.5}$ mass during the January 2010.

growth is about $10 \%$ (Fig. 7). Motorcycles, which are mainly gasoline fueled vehicles, are the largest fleet and comprise about $35 \%$ of the total vehicle population. Motor cars and jeep/station wagon/microbus are the next largest fleet component (about 34\%). Because of government policy, a large number of vehicles especially cars, taxis, and three wheelers are now operated on CNG (as of January 2011 over 0.12 million vehicles were converted to $\mathrm{CNG}$ ). The remaining vehicles are using either diesel or gasoline (BRTA, 2010). Heavy duty commercial vehicles comprising $19 \%$ of the total fleet are expected to be causing air pollution.

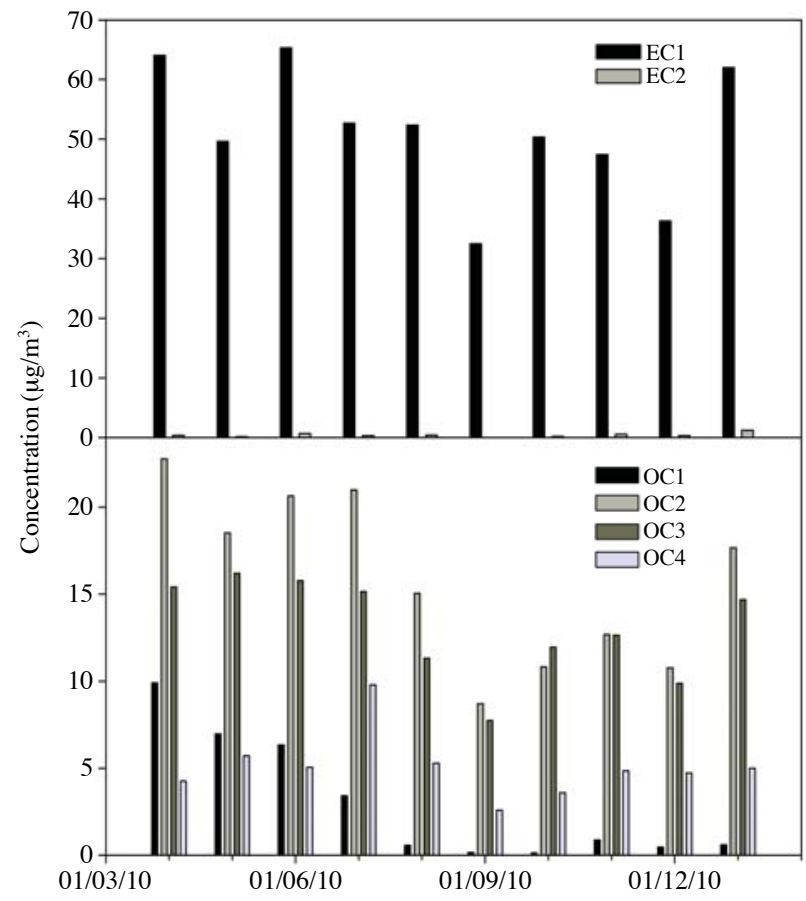

Fig. 6. Fractions of $\mathrm{OC} 1, \mathrm{OC} 2, \mathrm{OC} 3, \mathrm{OC} 4, \mathrm{EC} 1$, and $\mathrm{EC} 2$ in $\mathrm{PM}_{1}$ mass during January 2010.

\section{4 Trends in Particulate Matter and Black Carbon Mass Concentrations}

Long-term PM data (April 2000 to March 2006) and (April 2000 to March 2010) in two size fractions $\left(\mathrm{PM}_{2.2}\right.$ and $\left.\mathrm{PM}_{2.2-10}\right)$ obtained from two particulate air quality-monitoring stations, (HS and SR) were also analyzed to see the trend of air quality in Dhaka. The HS site is a heavily traffic-impacted site while the SR site is in a residential area. The sources of the observed PM for these sites have been extensively discussed in prior source apportionment studies (Begum et al., 2010, 2008, 2006a, b, 2004). 


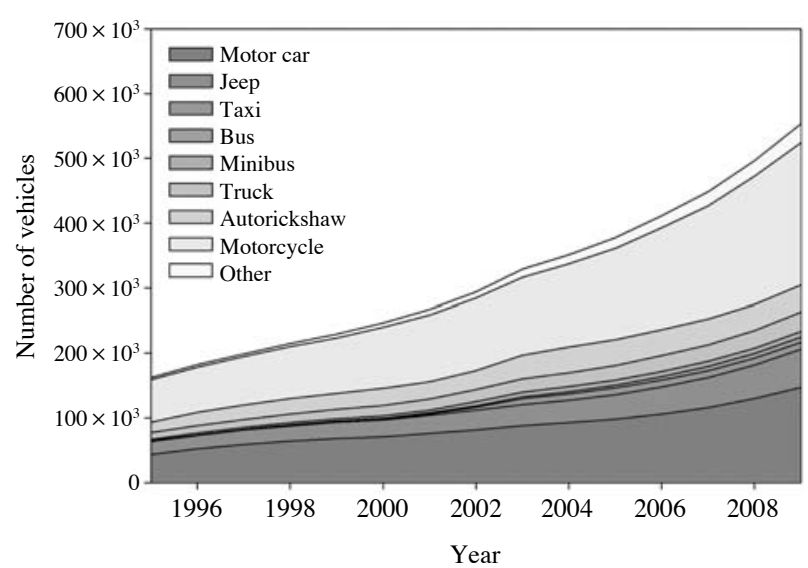

Fig. 7. Year-by-year registration of vehicles in Dhaka City (Source: Bangladesh Road Transport Authority, 2010).

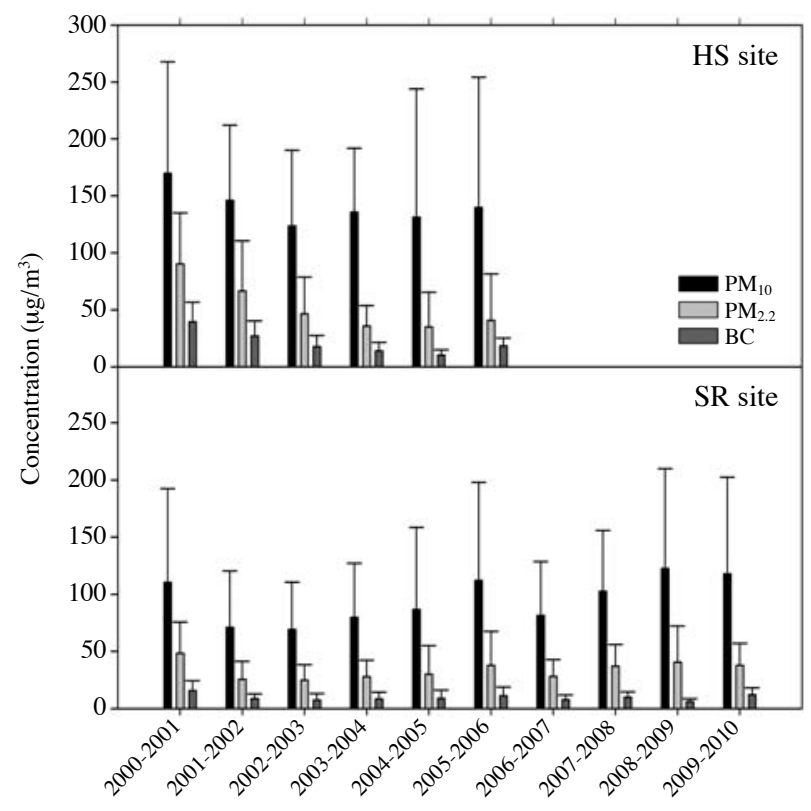

Fig. 8. The yearly average $\mathrm{PM}_{10}, \mathrm{PM}_{2.2}$ and $\mathrm{BC}$ mass concentrations from April 2000 to March 2006 and April 2000 to March 2010 at HS and SR sites respectively.

The year-by-year average values of $\mathrm{PM}_{10}, \mathrm{PM}_{2.2}$, and $\mathrm{BC}$ at mass concentrations obtained in these sites are presented in Fig. 8. From the figure, it can be observed that over the years, the $\mathrm{PM}_{2.2}$ mass concentration has decreasing trend while $\mathrm{PM}_{10}$ has increased, which suggests that $\mathrm{PM}_{2.2-10}$ fraction has been increasing. The decrease in fine particle mass is notable given the rise in the number of vehicles noted in Fig. 7. Thus, the policy approaches to reduce vehicular emissions have provided some of the improvements in the observed fine PM mass values.

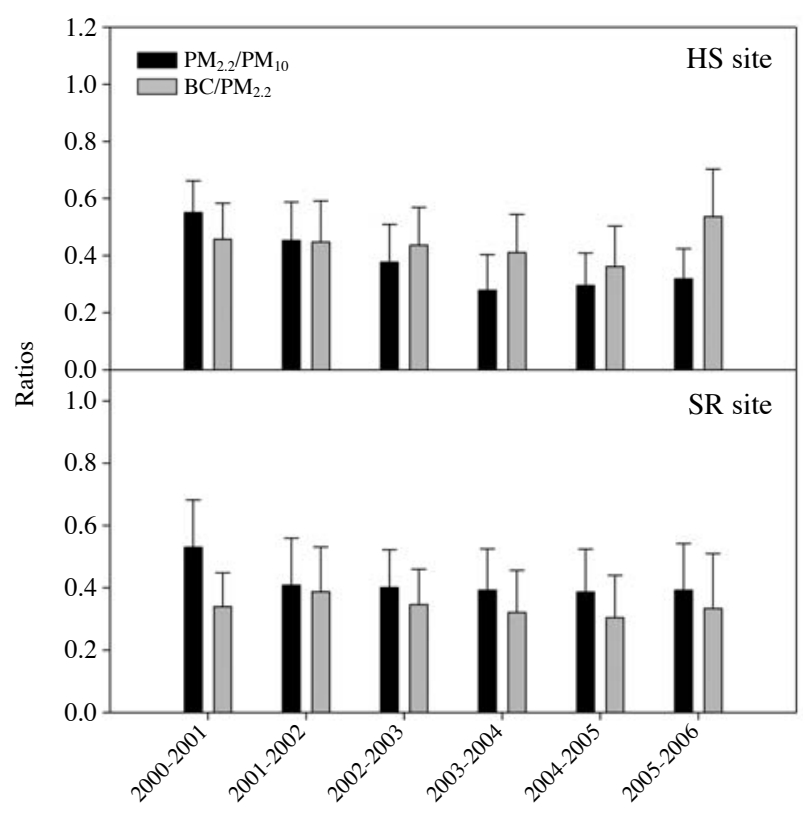

Fig. 9. Ratios of $\mathrm{PM}_{2.2} / \mathrm{PM}_{10}$ and $\mathrm{BC} / \mathrm{PM}_{2.2}$ over the collection periods from April 2000 to March 2006 and April 2000 to March 2010 at HS and SR sites respectively.

The reduction in $\mathrm{PM}_{2.2}$ fraction of the particulate pollution seems to be over compensated by increasing the coarse $\left(\mathrm{PM}_{10-2.2}\right)$ fraction and major portion of those particles are of natural origin. Increases in soil and road dust particles in the coarse fraction increase the $\mathrm{PM}_{10}$ mass concentration. About 60 to $70 \%$ of coarse mass is soil dust including road dust (Begum, 2011a) in the Dhaka air. BC concentrations also show a decreasing trend. Further policy interventions may also be require to reduce such coarse particles, which are mainly originated from soil, road dust and construction activities.

The yearly average $\mathrm{PM}_{2.2} / \mathrm{PM}_{10}$ and $\mathrm{BC} / \mathrm{PM}_{2.2}$ ratios are also shown in Fig. 9. It may be seen that after 2001 $/ 2003$ the average $\mathrm{BC} / \mathrm{PM}_{2.2}$ ratio remained unchanged although major sources such as vehicles have significantly increased. During this period, different policies were implemented to reduce the ambient PM concentrations. These measures included a phased reduction of gasoline-powered, two-stroke, three-wheel taxis with their complete banning as of January 2003 (Begum et al., 2006b), improved training of engine mechanics, and removal of trucks and buses that were more than 20 years old, and also electronic traffic signals.

It can be seen that the mean $\mathrm{PM}_{2.5}$ values were much higher than the 2006 USEPA PM National Ambient Air Quality Standards as well as the Bangladesh National Ambient Air Quality Standard for $\mathrm{PM}_{2.5}$. The $\mathrm{PM}_{10}$ concentrations are much higher than the WHO annual 
Table 3. Average source contributions derived from the PMF modeling for the SR site.

\begin{tabular}{|c|c|c|c|c|c|c|c|c|}
\hline \multirow{3}{*}{ Source } & \multicolumn{4}{|c|}{$2001-2005$} & \multicolumn{4}{|c|}{$2005-2006$} \\
\hline & \multicolumn{2}{|c|}{ Fine sample } & \multicolumn{2}{|c|}{ Coarse sample } & \multicolumn{2}{|c|}{ Fine sample } & \multicolumn{2}{|c|}{ Coarse sample } \\
\hline & $\%$ & $\operatorname{Mass}\left(\mathrm{ng} / \mathrm{m}^{3}\right)$ & $\%$ & Mass $\left(\mathrm{ng} / \mathrm{m}^{3}\right)$ & $\%$ & $\operatorname{Mass}\left(\mathrm{ng} / \mathrm{m}^{3}\right)$ & $\%$ & $\operatorname{Mass}\left(\mathrm{ng} / \mathrm{m}^{3}\right)$ \\
\hline Soil dust & 14.8 & 2934 & 43.8 & 15055 & 9.41 & 2735 & 48.9 & 26392 \\
\hline Zn source & 3.53 & 701 & 5.20 & 1786 & 6.68 & 1943 & 2.03 & 1094 \\
\hline Brick kiln & 18.7 & 3709 & & & 38.1 & 11085 & & \\
\hline Road dust & 3.56 & 707 & 2.21 & 758 & 17.7 & 5141 & 12 & 6483 \\
\hline Metal smelter & 0.67 & 133 & 4.97 & 1708 & 6.68 & 1942 & 0.89 & 478 \\
\hline Sea salt & 4.34 & 862 & 5.26 & 1807 & 2.07 & 602 & 9.87 & 5322 \\
\hline Motor vehicle & 54.4 & 10797 & 38.6 & 13259 & 19.3 & 5622 & 26.3 & 14179 \\
\hline $\mathrm{RM}$ & & 19842 & & 34373 & & 29070 & & 53947 \\
\hline MM & & 26217 & & 44970 & & 30514 & & 56590 \\
\hline
\end{tabular}

guideline 2005 mean of $20 \mu \mathrm{g} / \mathrm{m}^{3}$ and a 24 -hour value of $50 \mu \mathrm{g} / \mathrm{m}^{3}$.

Source apportionments results obtained from previous Positive Matrix Factorization (PMF) analysis on both fine and coarse fractions in SR site were obtained are given in Table 3 (Begum et al., 2011a, 2010). It was observed that the contributions of motor vehicles in fine PM fraction has decreased in 2005-2006 than the previous year, but the contribution from brick kilns increased. This decrease resulted from the conversion of about $50 \%$ of vehicles to CNG. The brick industry in Bangladesh produces 15 billion bricks per year with an annual growth of about $7-8 \%$ and contributes $1 \%$ of the GDP. It consumes 2.2 million tons of coal and 1.9 million tons of fire wood. Thus, the increased size of the brick industries has driven increases in PM emission. It is also seen that number of motor vehicles, which are believed to be a major combustion source for air pollution, have increased. However, the relative $\mathrm{BC}$ fraction in $\mathrm{PM}_{2.2}$ fraction has not increased over the years (Fig. 9) possibly resulting from significant reductions in the carbonaceous emissions by vehicular related sources.

\section{CONCLUSIONS}

In order to improve the ambient air quality of Dhaka, the government has implemented several policy interventions since 1999 including introducing unleaded gasoline, banning of two stroke auto-rickshaws and switching fuel to compressed natural gas (CNG). Although a large fraction of the automobiles, especially the smaller vehicles in Dhaka are now running on CNG, but CNG-converted engines use gasoline to start the engine. Moreover, long distance buses and trucks still operate using diesel. Therefore, the use of gasoline and diesel in transport sector has not been eliminated. Heavy-duty commercial vehicles and motor cycles that constitute about $54 \%$ of the total fleet continue to contribute to the air pollution in Dhaka.

In this study, carbon analyses have shown the signature of gasoline-fueled vehicles. It is observed that a significant fraction $(\sim 63 \%)$ of $\mathrm{PM}_{2.5}$ is $\mathrm{PM}_{1}$. It also seen that $\mathrm{PM}_{1}$ fractions contain the majority of total carbonaceous materials in the $\mathrm{PM}_{2.5}$. Carbon fraction analysis showed that the contribution of gasoline is much larger than from diesel with respect to carbonaceous material in the PM because of changes to vehicle characteristics in Dhaka city. Although carbonaceous materials in PM are likely to arise from combustion sources, the small number of samples does not permit the separation of their individual contributions. Further study will be necessary to determine the air quality impacts of the brick industry.

Source apportionment results showed that vehicular exhaust remain the single largest contributor to PM in Dhaka. Various government policy interventions have reduced PM pollution levels including carbonaceous materials that showed a decreasing trend over the years. With the increasing economic activities and GDP growth, the number of vehicles and brick kilns is increasing significantly in and around Dhaka. Further action will be required to further reduce the PM related air pollution in Dhaka.

\section{REFERENCES}

Andreae, M.O., Crutzen, P.I. (1997) Atmospheric aerosols: Bio-geochemical sources and ole in atmospheric chemistry. Science 276, 1052-1056.

Begum, B.A., Biswas, S.K. (2005). Comparison of PM collection efficiency of Gent and Airmatrics MiniVol Portable Air Sampler. Nuclear Science and Application I14, 79-83.

Begum, B.A., Biswas, S.K., Hopke, P.K. (2006a) Impact of banning of two-stroke engines on airborne particulate matter concentrations in Dhaka, Bangladesh. Jour- 
nal of the Air and Waste Management Association 56, 85-89.

Begum, B.A., Biswas, S.K., Hopke, P.K. (2006b) Temporal variations and spatial distribution of ambient PM2.2 and PM10 concentrations in Dhaka, Bangladesh. The Science of the Total Environment 358, 36-45.

Begum, B.A., Biswas, S.K., Hopke, P.K. (2008). Assessment of trends and present ambient concentrations of PM2.2 and PM10 in Dhaka, Bangladesh. Air Quality, Atmosphere, and Health 1, 125-133.

Begum, B.A., Biswas, S.K., Hopke, P.K. (2010) Identification of sources of fine and coarse particulate matter in Dhaka Bangladesh. Aerosol \& Air Quality Research 10, 345-353.

Begum, B.A., Biswas, S.K., Hopke, P.K. (2011a) Key issues in controlling air pollutants in Dhaka, Bangladesh. Atmospheric Environment doi:10.1016/j.atmosenv. 2010.10.022.

Begum, B.A., Biswas, S.K., Pandit, G.G., Saradhi, I.V., Waheed, S., Siddique, N., Seneviratne, M.C.S., Cohen, D.D., Markwitz, A., Hopke, P.K. (2011b) Long-range transport of soil dust and smoke pollution in the South Asian region. Atmospheric Pollution Research 2, 151157.

Begum, B.A., Kim, E., Biswas, S.K., Hopke, P.K. (2004) Investigation of sources of atmospheric aerosol at urban and semi-urban areas in Bangladesh. Atmospheric Environment 38, 3025-3038.

Biswas, S.K., Tarafder, S.A., Islam, A., Khaliquzzaman, M. (2001) Investigation of sources of atmospheric particulate matter (APM) at an urban area in Bangladesh, Report/AECD/CH/55.

Biswas, S.K., Tarafdar, S.A., Islam, A., Khaliquzzaman, M., Tervahattu, H., Kupiainen, K. (2003) Impact of unleaded gasoline introduction on the concentration of lead in the air of Dhaka, Bangladesh. Journal of the Air and Waste Management Association 53, 1355-1362.

BRTA (Bangladesh Road Transport Authority) (2010) www.brta.gov.bd.

Cass, G.R., Boone, P.M., Macias, E.S. (1982) Emissions and air quality relationships for atmospheric carbon particles in Los Angeles. In Particualte Carbon: Atmospheric Life Cycle (Wolf, G.T. and Klimisch, R.L. Eds), Plenum Press, New York.

Chow, J.C., Watson, J.G., Chen, L.-W.A., Arnott, W.P., Moosmüller, H., Fung, K.K. (2004). Equivalence of elemental carbon by Thermal/Optical Reflectance and Transmittance with different temperature protocols. Environmental Science Technology 38, 4414-4422.

Chow, J.C., Watson, J.G., Lowenthal, D.H., Magliano, K.L. (2008) Size-resolved aerosol chemical concentrations at rural and urban sites in Central California, USA. Atmospheric Research 90, 243-252.

Chow, J.C., Watson, J.G., Prichett, L.C., Pierson, W.R., Frazier, C.A., Purcell, R.G. (1993) The DRI thermal/ optical reflectance carbon analysis system: description, evaluation and applications in U.S. air quality studies. Atmospheric Environment 27, 1185-1201.
Cohen, D.D., Graham, M., Bailey, M., Kondepudi, R. (1996) Elemental analysis by PIXE and other IBA techniques and their application to source fingerprinting of atmospheric fine particle pollution. Nuclear Instruments and Methods (B) 109, 218-226.

Hansen, J., Nazarenko, L. (2004) Soot climate forcing via snow and ice albedos. Proceedings of the National Academy of Sciences 101, 423-428.

Hopke, P.K., Xie, Y., Raunemaa, T., Biegalski, S., Landsberger, S., Maenhaut, W., Artaxo, P., Cohen, D. (1997) Characterization of Gent stacked filter unit PM10 sampler. Aerosol Science and Technology 27, 726-735.

Jacobson, M.Z. (2001) Strong radiative heating due to the mixing state o black carbon in atmospheric aerosols. Nature 409, 695-697.

Kehrwald, N.M., Thompson, L.G., Tandong, Y., Thompson, E.M., Schotterer, U., Alfimov, V., Beer, J., Eikenberg, J., Davis, M.E. (2008) Mass loss on Himalayan glacier endangers water resources. Geophysical Research Letters 35, L22502.

Kim, K.H., Sekiguchi, K., Kudo, S., Sakamoto, K. (2011) Characteristics of atmospheric elemental carbon (Char and Soot) in ultrafine and fine particles in a roadside environment, Japan. Aerosol and Air Quality Research 11, 1-12.

Koelmans, A.A., Jonker, M.T.O., Cornelissen, G., Bucheli, T.D., van Noorrt, P.C.M., Gustafsson, O. (2006) Black carbon: The reverse of its dark side. Chemosphere 63, 365-377.

Landsberger, S., Creatchmam, M. (1998) Elemental analysis of airborne particles, Boca Raton, FL: CRC Press, Inc.

Maenhaut, W., Salma, I., Cafmeyer, J., Annegarn, J.H., Andreae, M.O. (1996) Regional atmospheric aerosol composition and sources in the eastern Transvaal, South Africa and impact of biomass burning. Journal of Geophysical Research 101, 23631-23650.

Paul, S.K. (2007) Indoor air pollution from particulate matter emissions in different households in rural areas of Bangladesh, M.Sc. thesis, Department of Physics, Jahangirnagar University (Bangladesh).

Poschl, U. (2005) Atmospheric aerosols: Composition, transformation, climate and health effects. Angewante Chemie. International Edition 44, 7520-7540.

Ramanathan, V., Carmichael, G. (2008) Global and regional climate changes due to black carbon. Nature Geosciences 1, 221-227.

Rau, J.A. (1989) Composition and size distribution of residential wood smoke particles. Aerosol Science and Technology 10, 181-192.

Salako, G.O., Hopke, P.K., Cohen, D.D., Begum, B.A., Biswas, S.K., Pandit, G.G., Chung, Y.-S., Rahman, S.A., Hamzah, M.S., Davy, P., Markwitz, A., Shagjjamba, D., Lodoysamba, S., Wimolwattanapun, W., Bunprapob, S. (2011) Exploring the variation between EC and BC in a variety of locations. Aerosol, Air Quality Research, submitted.

Salam, A., Bauer, H., Kassin, K., Ullah, S.M., Puxbaum, 
H. (2003) Aerosol chemical characteristics of a megacity in Southeast Asia (Dhaka, Bangladesh). Atmospheric Environment 37, 2517-2528.

UNEP and C4 (2002) The Asian Brown Cloud: Climate and other Environmental Impacts UNEP, Nairobi, URL: http://www.rrcap.unep.org

Venkaraman, C., Reddy, C.K., Josson, S., Reddy, M.S. (2002) Aerosol size and chemical characteristics at Mumbai, India, during the INDOEX-IFP (1999). Atmospheric Environment 36, 1979-1991.

Watson, J.G., Chow, J.C., Lowenthal, D.H., Pritchett,
L.C., Frazier, C.A., Neuroth, G.R., Robbins, R. (1994). Differences in the carbon composition of source profiles for diesel- and gasoline-powered vehicles. Atmospheric Environment 28, 2493-2505.

Williams, D.J., Milne, J.W., Quigley, S.M., Roberts, R.B., Kimberlee, M.C. (1989) Particulate emissions from 'inuse' motor vehicles-II. Diesel vehicles. Atmospheric Environment 23, 2647-2661.

(Received 12 May 2011, revised 30 September 2011 accepted 30 September 2011) 